\title{
The Impact of Gasoline Price Fluctuations on Lodging Demand for US Brand Hotels
}

\author{
Kate Walsh, Cathy A. Enz, Linda Canina \\ Cornell University
}

\begin{abstract}
Analyzing US brand hotels, over a 13-year period, this study provides empirical evidence of a significant negative relationship between gasoline prices and demand for certain lodging products, controlling for economic factors (i.e. gross domestic product and population density). Applying principles from microeconomic demand theory to the literatures on gasoline price elasticities, consumer demographics and lodging demand, a set of hypotheses were devised to test the relationship between gasoline prices and lodging demand for specific hotel locations and price segments. Using fixed effects models, the results reveal that lodging demand decreases as gasoline prices rise in all segments except upper-upscale and all locations except urban areas. Hotels in midscale without food and beverage and economy market segments, in resort, suburban and highway locations, exhibit the greatest association between gasoline price shifts and demand. Implications of these findings are discussed for both hospitality research and practice.
\end{abstract}

\section{Introduction}

Gasoline prices have long been thought to alter consumer travel choices. When the price of gasoline goes up, it is often speculated that the consumption of lodging services will go down. Lodging providers, chambers of commerce, and even quick service restaurant chains have expressed concern that rising fuel prices affect summer highway travel plans, which in turn, affect sales volume (Zuber, 2001). Speculation on and assertions of the negative relationship between gasoline prices and lodging demand abound, but careful empirical studies do not. The addition of empirical investigations would serve to either support or refute conventional wisdom, and refine the nature and scope of the relationship between gasoline prices and lodging demand. Specifically, careful study would help to clarify the magnitude of a change in gasoline prices on lodging demand, and the type of lodging choices most associated with gasoline price fluctuations. 
The purpose of this study is to examine the relationship between gasoline price fluctuations and lodging demand. Of particular interest is an exploration of the magnitude of this relationship for various lodging product types in different locations. This article argues that because of the impact on the cost of travel and on consumers' purchasing power, consumer sensitivity to fluctuations in gasoline prices affects travel decisions and hence alters lodging demand. It is hypothesized that the impact of rising fuel costs on the cost of travel varies across locations due to differences in the availability of transportation substitutes. In addition, the impact of rising gasoline prices on consumers' purchasing power varies across lodging market segments, since the average income level of consumers across lodging segments is different. In light of recent events in the aftermath of September 11th, specifically resurgence in regional automobile travel, the impact of gasoline price changes on hotel demand may be of greater interest to a growing number of hotel and travel-related operators. The overarching goal of this work is to assist the hotel industry in anticipating and understanding the role of an important economic factor that influences consumer demand and may affect operating performance.

This article has several sections. First, the literature on the linkages between gasoline prices, travel consumption, and lodging demand is reviewed. The empirical literature on fuel prices linked to lodging demand is in its infancy; nevertheless, to develop testable hypotheses, the limited existing work on gasoline prices and consumer demand, the economics literature on consumer choice, and the economic-based literature on lodging demand is explored. The next sections discuss the research methodology and results of this study. The article concludes with a discussion of the implications of the findings for future research and management practice.

\section{Gasoline Prices, Consumer Choice, and Lodging Demand}

The automobile is a major mode of transportation in America. As evidence of the heavy reliance on this means of travel, by 1990, the US was responsible for one-third of the world oil consumption, two-thirds of which was used for transportation (Gately, 1990). Americans continue to be highly dependent on their automobiles for travel. As a result, gasoline consumption patterns are important to the lodging industry and may profoundly affect consumption patterns, including the choice to travel. Regrettably, there is no empirical literature that directly links gasoline prices to lodging consumption, hence the literature on gasoline consumption, microeconomic theory and lodging demand is used to offer indirect evidence for the relationships of interest in this study and build the empirical connection between gasoline price patterns and lodging demand. 


\section{The Behaviors of Gas Consumers}

The literature on gasoline consumption follows two distinct paths. The first path examines the relationship between consumer demographic profiles and gasoline consumption, while the second stream investigates the effect of pricing on gasoline consumption. According to the first stream of research, the demand for gasoline varies across consumer demographic profiles. Greening et al. (1995) conclude that the demand for gasoline is a function of households' driving requirements. For example, those living in rural areas tend to drive more than those living in suburban and urban areas. Studies have also revealed that gasoline demand is lower for those who live in the Northeast and Pacific regions of the country, where alternative forms of urban transportation are generally more available and sophisticated. In addition, Schmalensee and Stoker (1999) report that on average, young single adults (less than 35 years old) tend to drive more than other categories of individuals, such as older and/or married adults (Schmalensee and Stoker, 1999). Lastly, households where both spouses work tend to consume more gasoline than households where only one spouse works (Kayser, 2000). It is evident from these studies that gasoline consumption varies by consumer profile, suggesting that hotel products that address the needs of different consumers will be affected differently by gasoline price fluctuations.

The second body of existing work focuses on gasoline pricing and consumption. Numerous studies have examined the price elasticity of gasoline demand (Dahl and Sterner, 1991). The price elasticity measures changes in quantity demanded as a result of changes in price (Henderson and Quandt, 1980). The larger the percentage change in demand, in absolute value, the more responsive is demand to price variations. Price elastic consumers are said to be price sensitive because for a $1 \%$ change in price, their quantity demanded changes by at least $1 \%$. In contrast, those who demonstrate lower price elasticity are less sensitive to rising prices and will change their consumption by less when a product's price rises (Henderson and Quandt, 1980). Schmalensee and Stoker (1999) found that lower income households ( $\$ 12,000$ or less) dramatically curtail gasoline consumption as gasoline prices increase. Alternatively, consumers with higher incomes $(\$ 70,000$ or more) display greater price inelasticity, meaning that changes in gasoline prices do not dramatically affect their gasoline consumption (Schmalensee and Stoker, 1999). These results compliment those of an earlier study which found the most price sensitive (i.e. price elastic) behaviors to be among the retired or unemployed. Similarly, the most price insensitive (i.e. price inelastic) behaviors were among "traditional, nuclear, white-collar families" (Greening et al., 1995). If gasoline consumption is diminished for price sensitive consumers when the price of gasoline increases, by extension, their travel plans will be curtailed. 
Indirectly these studies point to a negative relationship between gasoline price increases and demand for certain lower-priced types of lodging products.

\section{The Behaviors of Lodging Consumers}

Economic-based research seeks to explain lodging demand by focusing on a variety of key variables. Numerous studies have examined influences on lodging demand, including explorations of room rates and gross domestic product (i.e. Coopers and Lybrand, 1995; Wheaton and Rossoff, 1998), room taxes (i.e. Fuji et al., 1980; Heimstra and Ismail, 1993) and substitutes and complements (Damonte et al., 1998/1999). Other studies on travel demand have also examined the role of consumer income, pricing and transportation costs (Crouch, 1994; Wicks et al., 1994). Yet, none of these studies have examined the impact of gasoline prices on lodging demand.

What has been revealed empirically is that lodging demand varies as a function of consumer demographics. One recent study found that four demographic factors greatly impact lodging demand: income, occupation, gender and age, accounting for approximately $44 \%, 35 \%, 14 \%$ and $12 \%$ of the variance in lodging demand, respectively (Palakurthi and Parks, 2000). More specifically, households with over $\$ 35,000$ in income, and whose members are between 35 and 54 years old, are one of the most important segments to the lodging industry. In addition, males average higher lodging demand than females and perhaps not surprisingly, managers and professionals comprise the most significant portion of lodging demand.

These findings suggest that different types of hotels cater their product to different types of consumers, depending on factors such as consumers' levels of income and reasons for travel. The implication is that these consumers have different price elasticities in response to increases in the cost of gasoline. For example, lower income consumers will be affected relatively more by gasoline price increases than will higher income consumers. And, higher gasoline consumers will also be more affected than lower gasoline consumers. Thus, extending the logic, gasoline prices may act as an important explanatory factor of lodging demand, particularly when the lodging product is consumed by a price sensitive customer.

Surprisingly, the empirical literature on the impact of gasoline prices on lodging demand is sparse. While consumer demographic profiles tell us something about the types of customers who are price sensitive and alter their demand for both gasoline and room nights, these studies fail to address the direct link between gasoline price fluctuations and lodging demand. Applying basic principles from microeconomic demand theory to the literatures on gasoline price elasticities, consumer demographics 
and lodging demand, a set of hypotheses were devised to test the relationships between gasoline prices and lodging demand for specific hotel locations and price segments.

\section{Gas Prices and Lodging Demand: Hypotheses}

The first hypothesis follows directly from the basic principles of microeconomic demand theory and the current literature on gasoline demand. Since gasoline is a factor positively affecting the cost of travel, it is expected that lodging demand will decline as gasoline prices increase. For most goods, there is an inverse relationship between the price of a complementary good and the quantity demanded (Henderson and Quandt, 1980; Kreps, 1990). In the case of lodging, gasoline prices are a component of the total cost of travel; therefore, gasoline is considered a complementary good for lodging demand. The literature demonstrates that gasoline consumption declines when gasoline prices rise (Schmalensee and Stoker, 1999). As gasoline prices increase, the cost of travel will increase and real income will fall. As a result, the willingness to travel will drop, resulting in a decrease in the demand for lodging services.

Overall economic conditions can have a profound affect on lodging demand. As the literature shows (Coopers and Lybrand, 1995; Wheaton and Rossoff, 1998), gross domestic product (GDP) in particular, shapes demand for hotel products, and is a reasonable indicator of overall economic health. That is, to assure that general economic conditions over time are not unduly affecting the hypothesized relationships, they need to be controlled, as the following hypothesis notes:

H1: A negative relationship will exist between gasoline price increases and the demand for lodging products, holding general economic conditions constant.

\section{The Role of Income}

One component of the total impact of a price change on the quantity demanded is commonly referred to in microeconomics as the income effect. This effect predicts that the gasoline price elasticity for lodging services will vary across income levels (Henderson and Quandt, 1980; Kreps, 1990). As prices increase, real income falls, negatively impacting demand. The impact of a price change on real income is positively related to the proportion of total income dedicated to the good. This effect implies that consumers' gasoline price sensitivity is positively related to the proportion of total income allocated to gasoline consumption. For example, if gasoline consumption represents $10 \%$ of one household's total income and $1 \%$ of another's, as the price of gasoline increases, gasoline consumption will change more profoundly for the former household than the latter, because real income has decreased by comparatively more. Thus, when prices change, the income effect will influence the quantity demanded 
of the good, and the impact will vary inversely with income level. As income levels increase, sensitivity to gasoline price fluctuations will be less. That is, those at higher income levels are less likely to alter their lodging demand when gasoline prices increase.

To explore the income effect, it is argued that lodging demand for hotels in lower price segments will be more strongly related to gasoline price fluctuations than will lodging demand for hotels in higher price segments because their products and services are targeted to the more price sensitive consumer. This logic follows from the presumption that lower income groups frequent the lower price segment properties and their patterns of consumption are relatively more subject to income effects. Price sensitive consumers will be more sensitive to rising gasoline prices, will reduce their consumption of most goods and services and hence will be more likely to choose not to travel. Since this cost conscious consumer group frequents lower priced hotels, this segment will experience the most significant drops in demand when gasoline prices shift upward. Consistent with the literature, lodging demand for hotels in lower price segments will be more sensitive to gasoline price fluctuations because of the consumption behaviors of their target consumers; hence the second hypothesis as follows:

H2: A stronger negative relationship will exist between gasoline price increases and lodging demand in lower priced hotel segments than in higher priced hotel segments, holding general economic conditions constant.

The Role of Hotel Location

Some hotel products are more dependent on automobile travel for consumers than others. As a result, it is expected that hotel location will also be an important factor in the relationship between gasoline prices and lodging demand. The number of transportation alternatives varies substantially by location, with some locations being accessible only by car because of their remote locations, and others being accessible by substitutes like train, taxicab, airlines, bus, and other forms of travel. The existence of numerous travel alternatives varies across hotel property locations, making location a key factor in understanding the relationship between gasoline prices and demand for lodging.

To place the importance of location in the context of theory, the role of substitutes is illuminating. An important economic factor argued to link gasoline price fluctuations to lodging demand is the availability of substitute forms of travel. Microeconomic theory predicts that as the number of alternatives increase, the cross price elasticity of demand will be less sensitive. A cross-price elasticity of demand measures the demand response for one good when the price changes for one of its complementary goods (Henderson and Quandt, 1980; Kreps, 1990). 
For example, in urban locations there are many forms of travel that are not immediately affected by changes in gasoline prices, such as public transportation costs. Public transportation costs on buses, subways and taxis are less volatile because of regulated prices. As a result, their fares do not as closely reflect the current market prices of gasoline. Since these other forms of transportation exist, it is argued that gasoline price changes will have a relatively smaller impact on lodging demand in these locations than it will on hotels in locations serviced by fewer transportation alternatives. Hotels located on highways and to a lesser degree in suburban areas are more reliant on the automobile as the primary form of consumer travel and have fewer substitutes. Hence, it is expected that lodging demand in these locations will be more strongly related to gasoline price changes than will lodging demand in locations with more transportation substitutes available to consumers.

While this research argues that hotels in locations that are more exclusively serviced by automobile, drive-to destinations are more sensitive to fluctuations in gasoline prices, resort hotels pose a unique case since special travel accommodations are often included with this product. Even in remote or drive-to locations, resorts provide special transportation from urban locations via bus or minivan. Determining the accessibility of multiple forms of transportation to resort hotels in the US is not easy to discern. Hence, it is speculated that overall lodging demand at resorts will be less sensitive to fluctuations in gasoline prices, both because of the provision of additional forms of ground transportation and also because the income effect is expected to be minimal since more resort consumers are high-end travelers. In summary, locations with fewer alternative modes of transportation will be far more likely to have lodging properties influenced by gasoline price changes.

H3. Lodging demand for hotels in highway and suburban locations will be more strongly related to gasoline price fluctuations than lodging demand for hotels in urban and resort destinations, holding general economic conditions constant.

\section{A Combination of Effects}

Combining the effects of price segment and location, it is expected that lodging demand for hotels in lower priced segments in locations in which few transportation substitutes exists will be the most profoundly shaped by gasoline prices. The income effect suggests that customers who frequent lower priced hotels are more sensitive to price changes. In addition, it is argued that because of the lack of transportation alternatives, customers of hotels along highways and in suburban locations will be the most sensitive to gasoline price fluctuations. Combining the income effect and the availability of transportation alternatives yields the expectation that lodging demand for hotels in economy and mid- 
scale hotels in highway and suburban locations will be the most sensitive to gasoline price fluctuations, as the final hypothesis suggests:

H4. Lodging demand for hotels in economy and mid-scale hotels in highway and suburban locations will be the most strongly associated with gasoline price fluctuations, holding general economic conditions constant.

Relying on microeconomic pricing theory and specifically the effects of income and alternative transportation choices, four hypotheses are offered as a first attempt to explore the relationship between gasoline prices and demand for branded hotels within the United States. These hypotheses carefully argue for the control of other key economic factors (i.e., GDP), and are supported by the existing literature on both gasoline and lodging demand. The next section presents a detailed discussion of the methodology, including the models devised to test these hypotheses.

\section{Methodology}

\section{Sample}

This study explores the relationship between gasoline prices and branded hotel lodging demand over a 13-year period from 1988 to 2000 . One of the advantages of using panel data over 13 years is that the results are less susceptible to seasonal fluctuations in both demand and gasoline pricing. The lodging data consists of monthly observations on rooms sold at the property level for the 1988-2000 period. To test the hypotheses, hotels located in four different types of locations were examined, including hotels in urban, suburban, highway, and resort locations. Hotels were also divided into five market segment categories, which included: upper upscale, upscale, mid-scale, both with and without food and beverage (F\&B) and economy. The location categories and market segment designations are consistent with those used throughout the industry and reflect the categorization scheme of Smith Travel Research and Pricewaterhouse Coopers.

\section{Dependent variable: lodging demand}

The dependent variable, annual lodging demand, was measured by aggregating the monthly property level hotel rooms sold. The unit of observation in this study is segment, $m$, in location, $l$, in state, $s$ in year t. Aggregation of the monthly property level demand data were necessary to ensure independence across the unit of observation and to maintain consistency with the other variables for which data were captured at the state and annual level. Since hotels in the same segment in the same 
location compete with one another, property level observations are not independent. To address this issue, data were aggregated across the competitive set, defined according to market segment and location within a state. Because gas prices are reported at the state level, it was necessary to aggregate the dependent variable to the state level. Further, since our control variables, GDP and population density, are annual indicators we aggregated the dependent variable to the annual level.

The underlying sample consisted of 20,000 hotels' property level data over the 13 -year period, 1988-2000, but the stratified samples used to test hypotheses $2-4$ varied according to the hotels included within each of the market and location subpopulations being examined. The lodging demand and property level data were obtained from Smith Travel Research (STR), an independent research organization that tracks lodging performance for all major North American chains. The hotel rooms sold data are comprehensive, and the data used for this study included a sample of hotels that captures over $98 \%$ of the brand hotel inventory, and is thus fully representative of the entire US lodging population for branded hotels. The availability of a comprehensive database for use in this research is a unique feature of the study, since it permits more targeted aggregation of individual property level data versus the more commonly available overall industry demand figures.

\section{Gasoline Prices}

The key independent variable was gasoline prices. This variable was obtained from the Bureau of Economic Analysis and captures gas prices by state for each of the 13 years. In order to be consistent with the observational frequency of the two control variables, GDP and population density (POPDEN), the annual average of monthly gasoline prices were computed. To determine whether aggregation masked important monthly gasoline price variations, the average within-year variation in real gasoline prices by month for the 13 years was computed and compared to the across-year variation. The analysis revealed that the within-year variation in gasoline prices was less than the across-year variation; hence using annualized gas prices were deemed appropriate.

\section{Control Variables}

Even though the objective of this study was to measure the relationship between gasoline prices and rooms sold, two control variables were included in the equation because of their potential to explain a substantial degree of the variation in lodging demand. First, to capture the influence of general economic prosperity on lodging demand, GDP was included in the equation. A failure to take into consideration the general economic conditions in the US would clearly result in a misspecified equation. 
As presented in the literature review, GDP is a key variable in explaining lodging demand. Annual GDP, obtained from the Bureau of Economic Analysis, was used.

Second, a population density variable was also included as a control for local economic conditions that may impact lodging demand. This variable was defined as the population by state divided by the state land area and was calculated for each year, consistent with current conceptualizations (Bunting et al., 2002). Population and state land area were obtained from the US Bureau of the Census. All dollar denominated variables were converted to 2000 real dollars using the consumer price index (CPI), obtained from the US Bureau of Labor Statistics.

\section{The Equation}

Below is the equation developed to test for the impact of gasoline prices on lodging demand, taking into consideration the general economic conditions, as measured by GDP and state level demand generators, as measured by POPDEN. To test the relationship between gasoline prices and lodging demand, a fixed effects, time-series cross-sectional regression analysis was used to estimate the parameters of several forms of the following equation:

(1)

$$
\begin{aligned}
& \ln (\text { ROOMS SOLD })_{t, s}^{l, m}=\alpha_{s, t}^{l, m}+\beta_{1}^{l, m} \ln (\text { POPDEN })_{t, s}+\beta_{2}^{l, m} \ln (G D P)_{t} \\
& \quad+\beta_{3}^{l, m} \ln (G A S P R I C E)_{t, s}+u_{s, t}^{l, m}
\end{aligned}
$$

where, I denotes urban, suburban, highway and resort locations; m denotes the upper upscale, upscale, mid-price with food and beverage, mid-price and economy market segments; $t$ denotes years between 1988 and 2000; $s$ denotes states from 1 to 50; $\ln (\text { ROOMS SOLD) })_{t, s}^{l, m}$ is the natural log of the sum of rooms sold across, properties in year $\mathrm{t}$, in state $\mathrm{s}$, by location, $I$, and by market segment, $\mathrm{m}$; $\ln (P O P D E N)_{t, s}$ is the natural log of population density in year $t$, in state, $\mathrm{s} ; \ln (\mathrm{GDP}) \mathrm{t}$ is the natural log of gross domestic product in constant 2000 dollars in year $t$; and $\operatorname{In}(G A S P R I C E)_{t, s}$ is the natural log of the gasoline price in year $\mathrm{t}$ for state $s$ in constant 2000 dollars.

Because the data sample consisted of a combination of cross-sectional and times series data we used a fixed effects model. The advantage of using this type of model is that it allows for differences in lodging demand across states, $s$, locations, l, segments, $s$ and time, t. If it were assumed there were no cross-sectional differences, all of the cross-sectional and times series observations could be pooled and 
an ordinary least squares (OLS) approach to testing could be used to estimate the parameters. However, if heterogeneity exists across the units of observation, then a fixed effects model is more appropriate. ${ }^{1}$

We tested for fixed effects in the data and the statistical evidence from these analyses were strongly in favor of this approach to model building. ${ }^{2}$ In our sample, the cross-sectional effect is $\propto_{s}^{l, .}$ specific to the cross-sectional unit. If it is assumed that the $\propto_{s}^{l, . \prime} s$ is the same across all units, ordinary least squares would provide consistent and efficient estimates. The error term $u_{s, t}^{l,}$ would have a zero mean and homoscedastic covariance matrix. However, if there are group specific effects, ordinary least squares will be biased. The fixed effects model takes $\propto_{s}^{l, .}$ to be a group specific constant term. This model controls for cross-sectional and times series heterogeneity resulting in an error structure of the form: $u_{s, t}^{l, .}=v_{s}^{l, m}+e_{t}+\varepsilon_{s, t}^{l, m}$ where, $\varepsilon_{s, t}^{l, m}$ is a classical error term with a zero mean and homoscedastic covariance matrix.

The dependent variable in this model is the natural $\log (\mathrm{In})$ of rooms sold. The independent variables include the natural $\log (\operatorname{In})$ of gasoline price, the natural $\log (\operatorname{In})$ of GDP and the natural $\log (\operatorname{In})$ of POPDEN. The continuous variables were transformed to natural logs (Ins) so that their coefficients could be interpreted as elasticities or the percentage change in rooms sold for a $1 \%$ change in the independent variable.

It should be noted that this equation is not the reduced form equation derived from an equilibrium economic model of the demand and supply for lodging rooms. The purpose of this equation is simply to measure the relationship between gasoline prices and lodging demand and to compare the relative impact of gasoline prices on lodging demand across locations and market segments.

To ensure that the independent variables included in the equation and the sample design are not impacting the sign and magnitude of the estimated parameters and statistics of the regression equation, multicollinearity and autocorrelation were examined. Multicollinearity is an important issue in regression models and to some extent, it will always be present since most data will never be orthogonal. The relevant question, in this study, is when the variances of the estimates are so affected by the intercorrelation of the regressors that the sign, relative magnitude and statistical significance of the gasoline variable parameter estimates should be questioned. In general, multicollinearity is a problem for evaluating estimates when: (1) small changes in the data, for example deleting a few observations, produce large changes in the estimates; (2) coefficients have very high standard errors

\footnotetext{
${ }^{1}$ For a detailed discussion of the fixed effects model see Greene (2000).

${ }^{2}$ Chung and Kalnins (2001) also used the fixed effects model because their data set pooled times series and cross sectional observations.
} 
and low significance levels even though they are jointly significant and the R-squared for the regression is quite high; and, (3) coefficients have the wrong sign or implausible magnitudes (Greene 2000). To test the severity of multicollinearity in the equation, the condition number of XOX (Belsey et al., 1980) was computed. ${ }^{3}$ The condition number of XOX is the square root of the largest characteristic root of XOX (after scaling each column so that it has unit length) to the smallest. It was determined that multicollinearity is not a problem after examining each of these issues. The severity of autocorrelation was tested by estimating the first-order correlation coefficient for each cross-section. ${ }^{4}$ The maximum value was 0.11 , not of a magnitude to cause concern regarding the validity of the results. The next section presents the results of testing the four hypotheses.

Table 1

The impact of gas prices on lodging demand

\begin{tabular}{lll}
\hline Lodging demand & Gas price & \\
\cline { 2 - 3 } & Coefficient & $t$-Statistic \\
\hline Overall & $-0.18^{* * *}$ & -6.85 \\
By market segment & & \\
Upper Upscale & $-0.16^{*}$ & -3.13 \\
Upscale & $-0.11^{*}$ & -1.80 \\
Midscale with F\&B & $-0.14^{* * *}$ & -4.01 \\
Midscale without F\&B & $-0.32^{* * *}$ & -4.58 \\
Economy & $-0.21^{* * *}$ & -3.93 \\
By hotel location & & \\
Urban & -0.01 & -0.25 \\
Resort & $-0.20^{*}$ & -1.97 \\
Suburban & $-0.27^{* *}$ & -5.47 \\
Highway & $-0.18^{* * *}$ & -3.45 \\
\hline
\end{tabular}

${ }^{*} p<0.05,{ }^{* *} p<0.01,{ }^{* * *} p<0.001$.

Note: This table reports the coefficients and t-values on the independent variable, gasoline price, controlling for, in all equations, GDP and population density in a fixed effects model.

\section{Results}

The results of this study are summarized in Tables 1 and 2. As Table 1 indicates, the first hypothesis was supported: an inverse relationship exists between gasoline prices and lodging demand. A $1 \%$ increase in gasoline prices actually yields a $0.18 \%$ decrease in lodging demand. The F-test for fixed

\footnotetext{
${ }^{3}$ Where $\mathrm{X}$ is the matrix of the independent variables in the data sample used in the regression analysis.

${ }^{4}$ See Parks (1967).
} 
effects is 149.03 , at $p<0.001 .^{5}$ This result confirms the assertion that there is a statistically significant inverse relationship between gasoline prices changes and lodging demand. As gasoline prices increase, the cost of travel increases, and purchasing power falls, which in turn, impacts the demand for lodging.

The second hypothesis, that lodging demand for hotels in lower price segments will be more sensitive to gasoline price fluctuations than lodging demand for hotels in higher price segments, was also supported. As shown in Table 1, the magnitude of the coefficients indicates that the strongest effect of gasoline prices on lodging demand was found in the midscale without F\&B segments, followed by the economy segment. The weakest significant effect was found for hotels in the upscale segment. All segments exhibited both negative and significant relationships (at po0:01 or stronger) with the exception of the upper upscale market; demand for rooms in this market was negatively but not significantly affected by changes in gasoline prices. Thus, the -0.21 coefficient for hotels in the economy market suggests that a $1 \%$ increase in gasoline prices reduces lodging demand for economy hotels by $0.21 \%$, while the -0.11 coefficient for hotels in upscale markets suggests that a $1 \%$ increase in gasoline prices reduces lodging demand for upscale hotels by $0.11 \%$. This pattern of negative and significant coefficients suggests that consumers of lower priced lodging products may reduce their consumption when gasoline prices increase.

Hypothesis 3, which states that lodging demand for hotels in highway and suburban locations will be more sensitive to gasoline price fluctuations than lodging demand for hotels in urban and resort destinations, was partially supported. As Table 1 indicates, a statistically significant relationship (po0:05 or stronger) was found for hotels in suburban, resort and highway locations. By examining the magnitude of the coefficients however, it is clear that demand for rooms in suburban locations is most sensitive to gas prices. A $1 \%$ increase in gasoline prices results in a $0.27 \%, 0.20 \%$ and $0.18 \%$ decrease in lodging demand in suburban, resort and highway hotels, respectively. Surprisingly, hotels in resort locations exhibited a slightly stronger negative relationship than hotels in highway locations. Not surprising was the finding that demand for urban hotels is not sensitive to fluctuations in gasoline prices.

\footnotetext{
${ }^{5}$ Since the estimated equation does not represent the reduced form equation of the simultaneous equation equilibrium model of the supply and demand of hotel rooms, an analysis of model fit was not performed.
} 
Table 2

The impact of gas prices on lodging demand by location and market

\begin{tabular}{|c|c|c|}
\hline \multirow[t]{2}{*}{ Location/market } & \multicolumn{2}{|l|}{ Gas Price } \\
\hline & Coefficient & $t$-Statistic \\
\hline \multicolumn{3}{|l|}{ Urban } \\
\hline Upper Upscale & $-0.21^{*}$ & -2.29 \\
\hline Upscale & -0.08 & -0.77 \\
\hline Midscale with F\&B & $-0.18^{* *}$ & -2.82 \\
\hline Midscale without F\&B & 0.22 & 0.95 \\
\hline Economy & 0.19 & 1.29 \\
\hline \multicolumn{3}{|l|}{ Suburban } \\
\hline Upper Upscale & $-0.29 * *$ & -2.84 \\
\hline Upscale & $-0.30^{*}$ & -2.44 \\
\hline Midscale with F\&B & -0.11 & -1.46 \\
\hline Midscale without F\&B & $-0.40 * * *$ & -3.62 \\
\hline Economy & $-0.30^{* * *}$ & -3.75 \\
\hline \multicolumn{3}{|l|}{ Highway } \\
\hline Upper Upscale & -0.08 & -0.64 \\
\hline Upscale & 0.08 & 0.53 \\
\hline Midscale with F\&B & $-0.13^{* *}$ & -2.75 \\
\hline Midscale without F\&B & $-0.36^{* *}$ & -2.99 \\
\hline Economy & $-0.35^{* * *}$ & -5.92 \\
\hline \multicolumn{3}{|l|}{ Resort } \\
\hline Upper Upscale & -0.08 & -0.73 \\
\hline Upscale & 0.06 & 0.19 \\
\hline Midscale with F\&B & -0.15 & -1.44 \\
\hline Midscale without F\&B & $-0.54^{*}$ & -1.98 \\
\hline Economy & -0.38 & -1.06 \\
\hline
\end{tabular}

$* p<0.05, * * p<0.01, * * * p<0.001$.

Note: This table reports the coefficients and t-values on the independent variable, gasoline price, controlling for, in all equations, GDP and population density in a fixed effects model.

The results of the fourth hypothesis concerning the combined effects of hotel location and market segment, is shown in Table 2. The argument, that demand for hotels in economy and midscale hotels in highway and suburban locations will be the most sensitive to gasoline price fluctuations, was supported. Hotels that demonstrated the greatest sensitivity to changes in gasoline prices were along highways and in suburban locations in both economy and midscale segments without food and beverage facilities (at $p<0.01$ or stronger). In addition, a significant relationship was found for midscale hotels with food and beverage in highway locations. A $1 \%$ increase in gasoline prices reduces lodging demand for midscale hotels without food and beverage and economy segments in suburban locations by $0.40 \%$ and $0.30 \%$, respectively. Similarly, a $1 \%$ increase in gasoline prices reduces lodging demand in 
midscale hotels without food and beverage, economy hotels and midscale hotels with food and beverage along highway locations by $0.36 \%, 0.35 \%$ and $0.13 \%$, respectively.

Interestingly, the largest statistically significant decreases in rooms sold were found in the midscale without food and beverage segment, for hotels in highway, suburban and resort locations. In fact, these types of hotels in resort locations demonstrated the strongest relationship in the study; for a $1 \%$ increase in gas prices, lodging demand decreases by $0.54 \%$ (at $p<0.05$ ). In addition, the upper upscale did not escape feeling the impact of gas price shifts. Hotels in these segments in urban and suburban locations demonstrated a statistically significant negative relationship of $-0.21($ at $p<0.05)$ and -0.30 (at $p<0.01$ ) respectively. Hotels in upscale markets in suburban locations also demonstrated a negative, statistically significant relationship $(-0.30$ at $p<0.05)$.

\section{Discussion}

This study is the first comprehensive empirical examination of the relationship between gasoline prices and lodging demand for US brand hotels, exploring the impact of shifting gasoline prices on hotel rooms sold within different markets, locations and a combination of both markets and locations. By determining both the direction and magnitude of gasoline's impact on the industry, this research deepens our understanding of lodging demand, specifically of one of the critical factors that affect its sensitivity.

The results suggest that fluctuations in gasoline prices are linked to consumer demand for hotel rooms. As conventional wisdom and microeconomics would suggest, for price sensitive consumers, increasing prices for one element of the travel experience will have a detrimental affect on demand for other aspects of travel, namely the hotel room. This study reveals that this negative relationship exists for almost all hotel locations and price segments. This study is important because it so clearly shows how a change in one component of travel is linked to demand for a complementary good such as a hotel room.

The magnitude of the effects of gas price changes on lodging demand noticeably varies by location and price segment. As expected, demand for hotel brands that position themselves as lower in price, is more profoundly affected by shifting gasoline prices than is demand for hotels in higher market segments. Yet interestingly, hotels in the midscale market with food and beverage facilities - not economy-demonstrated the strongest relationship. For consumers who frequent these mid to lower priced hotel products, such as families on vacation for example, it seems likely that the price of gasoline is far more likely to be a key element in their choice to travel or stay at home. The possibility of the 
income effect discussed earlier would suggest that these consumers will likely curtail their travel activity if their overall costs of travel, specifically automobile travel, increases and real income falls.

Hotel location also plays a pivotal role in shaping lodging demand according to the results of this study. Hotels that are located along highways and in suburban locations, outside of major metropolitan locations and accessed primarily via automobiles, are more vulnerable to shifts in gasoline prices. Yet, hotels in resort locations are slightly more strongly affected than hotels along highway locations. As the results reveal, resorts most sensitive to gasoline fluctuations are those in the lower-end price category, particularly midscale without food and beverage market segment. This finding provides strong evidence that vacationers who are on modest leisure trips to resort destinations are truly the most sensitive to rising gas prices. Even the economy hotel along the highway is less sensitive, but not by much, to the raising and lowering of gas prices. In short, it makes sense that the most vulnerable hotel operators are those reliant on the discretionary leisure travel needs of the low-end consumer.

Certainly this logic would support the fact that in this study, the strongest association between gas price shifts and lodging demand was for hotels in midscale without food and beverage price ranges in resort locations. The role of gasoline price increases may be a far greater threat to hoteliers in these locations than previously thought. These results provide tentative support for the speculation that fewer transportation alternatives in select domestic vacation and holiday locations contribute to more dramatic adjustments in rooms sold when gasoline prices change.

This study has the benefit of being based on data from the entire US lodging industry over a 13year time frame, a period in which the gasoline prices exhibited sharp spikes and drops. The data are not subject to a unique year or season of gasoline prices, nor does it focus on only one state or region within the United States. Dramatic short-term fluctuations and more nuanced shifts are accounted for and the results present, in essence, the pattern of the relationship between gasoline prices and lodging demand over an extended time. In addition, because the study captures over $98 \%$ of US branded hotels, the ability to generalize the findings is significant.

\section{$\underline{\text { Limitations and Extensions }}$}

While this study sought to explore only the relationship between gasoline price fluctuations and lodging demand, it would have been illuminating to have detailed property level market mix or demographic data on consumers, such as the income levels, travel distances, or purpose of travel. Regrettably, this information is often not gathered by hotel operators or others. Nevertheless, more and more hotel companies are beginning to explore data capture techniques, as IT technologies evolve and 
more hotels appreciate the value of consumer behavior for understanding hotel demand patterns. Clearly, obtaining consumer information would be valuable to better understand income effects in this and future studies.

Thus, as the hospitality industry becomes more sophisticated in data capture and management, a fruitful area from which to extend this research would be to bridge the literatures on the economic impact of gasoline price shifts, hospitality customer demographics and lodging demand. It would be fruitful for example, to determine consumer travel distances to understand their spending patterns, and to also incorporate a wider variety of transportation costs (e.g., airlines and trains) into an analysis of lodging demand. One area for future exploration is to develop and test causal models that examine hospitality demand patterns in response to economic shifts; this model could include customer demographic and business mix profiles. Such work could extend the contribution of this study by exploring the impact of gasoline prices on travel decisions for both leisure and business travelers. This type of modeling could shed further light on the interesting strong relationship between gas prices and midscale without food and beverage lodging demand for hotels in resort locations that our findings revealed.

\section{Conclusion}

Given the demonstrated relationships between rising gasoline prices and demand for most hospitality products, the findings in this study can help decision-makers understand likely shifts in occupancy when gasoline prices rise. Proactive marketing that might include promotional bundling to reduce gasoline costs, may be one of the possible ways to directly counteract the effects of this variable. This idea might be most fruitful for hotels in suburban and highway locations in the midscale without food and beverage and economy segments. The results of this study could be used by hoteliers in cooperation with state level travel groups to devise tourism packages and promotional materials that might entice price sensitive travelers. Anticipating and strategically planning for the full array of travel costs could be used to provide specific states with a competitive positioning advantage. Efforts to control transportation costs will directly influence lodging demand, as this study shows. Hence, a cooperative effort to reduce overall travel costs including those for transportation, may be in the best interests of state convention and traveler bureaus.

At the same time, these findings suggest that not all decision-makers need to worry that jumps in gasoline prices will affect their demand levels. In fact, only hotels in specific locations feel the pinch. Thus, the quick assumption that rising gasoline prices will affect summer travel plans, for example, may 
only be true for a specific segment in a specific location, such as midscale hotels in resort locations. In fact, examining the long-term impacts of gasoline price fluctuations on lodging demand for certain markets represents a practical way from which to build from these findings.

This study represents a first step in exploring the impact on lodging demand of price changes in complementary goods, specifically shifts in gasoline prices. Future work should be directed toward expanding the equation through the use of additional consumer behavior information and in doing so, help refine our understanding of the influence of this important economic factor on US hospitality lodging demand.

\section{Acknowledgements}

The authors gratefully acknowledge the assistance of Smith Travel Research and the Center for Hospitality Research in providing access to the comprehensive lodging performance database used in this study.

No individual hotel or chain identity was revealed to the researchers, and all information shared with Cornell University researchers is bound by agreements of non-disclosure and confidentiality. Only aggregate data will be provided in this report.

All authors contributed equally to this research project.

\section{References}

Belsley, D., Kuh, E., Welsh, R., 1980. Regression Diagnostics: Influential Data and Sources of Collinearity. Wiley, New York.

Bunting, T., Filion, P., Priston, H., 2002. Density gradients in Canadian metropolitan regions, 1971-96: differential patterns of central area and suburban growth and change. Urban Studies 39 (13), 2531-2552.

Chung, W., Kalnins, A., 2001. Agglomeration effects and performance: a test of the Texas lodging industry. Strategic Management Journal 22, 969-988.

Coopers and Lybrand, 1995. Unpublished manuscript.

Crouch, G.I., 1994. The study of international tourism demand: a review of findings. Journal of Travel Research 33, 12-23.

Dahl, C.A., Sterner, T., 1991. Analyzing gasoline demand elasticities: a survey. Energy Economics 13, 203-210. 
Damonte, L.T., Domke-Damonte, D.J., Morse, S.P., 1998/1999. The case for using destination-level price elasticity of demand for lodging services. Asia Pacific Journal of Tourism Research 3, 19-26.

Gately, A., 1990. The US demand for highway travel and motor fuel. The Energy Journal 11, 59-73.

Greene, W.H., 2000. Econometric Analysis. Prentice-Hall, Upper Saddle River, NJ.

Greening, L.A., Hann, T.J., Formby, J.P., Cheng, D.C., 1995. Use of region, life-cycle and role variables in the short-run estimation of the demand for gasoline and miles traveled. Applied Economics 27, 643-656.

Henderson, J.M., Quandt, R.E., 1980. Microeconomic Theory: A Mathematical Approach. McGraw-Hill, New York.

Hiemstra, S.J., Ismail, J.A., 1993. Incidence of the impacts of room taxes on the lodging industry. Journal of Travel Research 31, 22-26.

Kayser, H.A., 2000. Gasoline demand and car choice: Estimating gasoline demand using household information. Energy Economics 22, 331-348.

Kreps, D.A., 1990. A Course in Microeconomic Theory. Princeton University Press, Princeton, NJ.

Parks, R.W., 1967. Efficient estimation of a system of regression equations when disturbances are both serially and contemporaneously correlated. Journal of the American Statistical Association 62, 500-509.

Palakurthi, R.R., Parks, S.J., 2000. The effect of selected socio-demographic factors on lodging demand in the USA. International Journal of Contemporary Hospitality Management 12, 135-142.

Schmalensee, R., Stoker, T.M., 1999. Household gasoline demand in the United States. Econometrica 67, 645-662.

Wheaton, W.C., Rossoff, L., 1998. The cyclic behavior on the US lodging industry. Real Estate Economics $26,67-82$.

Wicks, B., Uysal, M., Kim, S., 1994. The effect of lodging prices on visitors' demand. Hospitality Research Journal 17, 51-61.

Zuber, A., 2001. QSR pumps up summer promos to compete with gasoline prices. Nation's Restaurant News 6, 49-52. 